\title{
Mechanistic Insight into the Phosphodiester Bond Hydrolysis of Nanozymes
}

\author{
Adam Pecina, ${ }^{1}$ Paolo Scrimin, ${ }^{2}$ Fabrizio Mancin, ${ }^{2}$ and Marco De Vivo ${ }^{1}$ \\ ${ }^{1}$ Laboratory of Molecular Modeling and Drug Discovery, Istituto Italiano di Tecnologia, Via Morego 30, \\ 16163 Genoa, Italy \\ Adam.Pecina@iit.it; Marco.DeVivo@iit.it \\ ${ }^{2}$ Dipartimento di Scienze Chimiche, Università di Padova, Via Marzolo 1, 35131 Padova, Italy
}

\section{Extended Abstract}

Gold nanoparticles (AuNPs) passivated with organic molecules can be functionalized to produce nanodevices with unique properties and applications, e.g. in pollutant removal, chemosensing, theragnostics and even catalysis. ${ }^{[1-6]}$ The AuNPs with intrinsic enzyme-like capabilities, so-called nanozymes, mimic an enzyme catalytic site by placing together several functions supposed to cooperate in the catalytic process. ${ }^{[7-10]}$ These multivalent systems having several copies of catalytically active functional groups do not only induce the cooperation of the reactive functions towards the acceleration of the cleavage process, but also allow many catalytic events to occur simultaneously. ${ }^{[11,12]}$

For instance, we have reported that $1.6 \mathrm{~nm}$ diameter gold cores coated with a monolayer of thiols bearing $\mathrm{Zn}$ (II)chelating 1,4,7-triazacyclonane (TACN) moiety are among the most efficient catalysts for the phosphodiester bond cleavage ${ }^{[13,14]}$ The nanocatalysis is always facilitated by catalytic $\mathrm{Zn}$ (II) ions on the surface of AuNPs, that is reminiscent of metaldependent nucleases. However, the fundamental nanozyme's behaviour at the level of the outer coating monolayer remains poorly understood. Interestingly, these studies also showed that the chemical structure of coating thiols greatly influenced nanoparticle's reactivity. In detail, the elongation of the ligand's linker, or the simple substitution of an alkyl chain with PEG moiety, caused a drop in activity $\left(k_{\text {cat }}\right)$ of up to a $\sim 10$-fold. ${ }^{[13]}$ A mechanical understanding of such a difference in catalytic efficiency is however still missing.

Recently, using MD simulations, we have demonstrated that functionalized AuNPs form transient binding pockets in the coating monolayer, resembling the active sites of enzymes. ${ }^{[15,16]}$ We have also shown that AuNPs can form pre-catalytic complexes with DNA, in solution. ${ }^{[14]}$ In this context, we used $\mu$ s-long atomistic simulations, flanked with NMR experiments, to further dissect the mechanistic origins of the catalytic power of nanonucleases. Our new comparative study focused on two structurally similar AuNPs with a significantly different activity. We showed how the specific structure and dynamics of the coating monolayer affect and tune their ability to form two-metal-ion catalytic sites. ${ }^{[17]}$

This project has received funding from the European Union's Horizon 2020 research and innovation programme under the Marie Sklodowska-Curie grant agreement No. 843117.

\section{References}

[1] Kotov, N. A., Inorganic Nanoparticles as Protein Mimics. Science 2010, 330 (6001), 188-189.

[2] Mancin, F.; Scrimin, P.; Tecilla, P., Progress in artificial metallonucleases. Chem Commun 2012, 48 (45), 5545-5559.

[3] Wei, H.; Wang, E. K., Nanomaterials with enzyme-like characteristics (nanozymes): next-generation artificial enzymes. Chem Soc Rev 2013, 42 (14), 6060-609.

[4] Giljohann, D. A.; Seferos, D. S.; Daniel, W. L.; Massich, M. D.; Patel, P. C.; Mirkin, C. A., Gold Nanoparticles for Biology and Medicine. Angew Chem Int Edit 2010, 49 (19), 3280-3294.

[5] Du, Y.; Sheng, H.; Astruc, D.; Zhu, M., Atomically Precise Noble Metal Nanoclusters as Efficient Catalysts: A Bridge between Structure and Properties. Chem Rev 2020, 120 (2), 526-622.

[6] Gabrielli, L.; Prins, L. J.; Rastrelli, F.; Mancin, F.; Scrimin, P., Hydrolytic Nanozymes. Eur J Org Chem 2020, 2020 (32), $5044-$ 5055.

[7] Liang, M.; Yan, X., Nanozymes: From New Concepts, Mechanisms, and Standards to Applications. Acc Chem Res 2019, 52 (8), 2190-2200. 
[8] Wu, J.; Wang, X.; Wang, Q.; Lou, Z.; Li, S.; Zhu, Y.; Qin, L.; Wei, H., Nanomaterials with enzyme-like characteristics (nanozymes): next-generation artificial enzymes (II). Chem Soc Rev 2019, 48 (4), 1004-1076.

[9] Korschelt, K.; Tahir, M. N.; Tremel, W., A Step into the Future: Applications of Nanoparticle Enzyme Mimics. Chemistry 2018, 24 (39), 9703-9713

[10] Mancin, F.; Prins, L. J.; Pengo, P.; Pasquato, L.; Tecilla, P.; Scrimin, P., Hydrolytic Metallo-Nanozymes: From Micelles and Vesicles to Gold Nanoparticles. Molecules 2016, 21 (8).

[11] Huang, Y.; Ren, J.; Qu, X., Nanozymes: Classification, Catalytic Mechanisms, Activity Regulation, and Applications. Chem Rev 2019, 119 (6), 4357-4412.

[12] Scrimin, P.; Cardona, M.; Prieto, C., Multivalency as a Design Criterion in Catalyst Development, Ch. 7, in "Catalyst Development in Multivalency: Concepts, Research \& Applications”, Huskens, J., Prins, L. J., Haag, R., Ravoo, B. J. Eds., John Wiley \& Sons Ltd. 2017.

[13] Diez-Castellnou, M.; Mancin, F.; Scrimin, P., Efficient Phosphodiester Cleaving Nanozymes Resulting from Multivalency and Local Medium Polarity Control. J Am Chem Soc 2014, 136 (4), 1158-1161.

[14] Czescik, J.; Zamolo, S.; Darbre, T.; Rigo, R.; Sissi, C.; Pecina, A.; Riccardi, L.; De Vivo, M.; Mancin, F.; Scrimin, P., A Gold Nanoparticle Nanonuclease Relying on a Zn(II) Mononuclear Complex. Angewandte Chemie 2021, 60 (3), 1423-1432.

[15] Riccardi, L.; Gabrielli, L.; Sun, X.; De Biasi, F.; Rastrelli, F.; Mancin, F.; De Vivo, M., Nanoparticle-Based Receptors Mimic Protein-Ligand Recognition. Chem 2017, 3 (1), 92-109.

[16] Sun, X.; Riccardi, L.; De Biasi, F.; Rastrelli, F.; De Vivo, M.; Mancin, F., Molecular-Dynamics-Simulation-Directed Rational Design of Nanoreceptors with Targeted Affinity. Angewandte Chemie 2019, 58 (23), 7702-7707.

[17] Pecina, A.; Rosa-Gastaldo, D.; Riccardi, L.; Franco-Ulloa, S.; Milan, E.; Scrimin, P.; Mancin, F.; De Vivo, M., On the Metal-Aided Catalytic Mechanism for Phosphodiester Bond Cleavage Performed by Nanozymes; under review. 